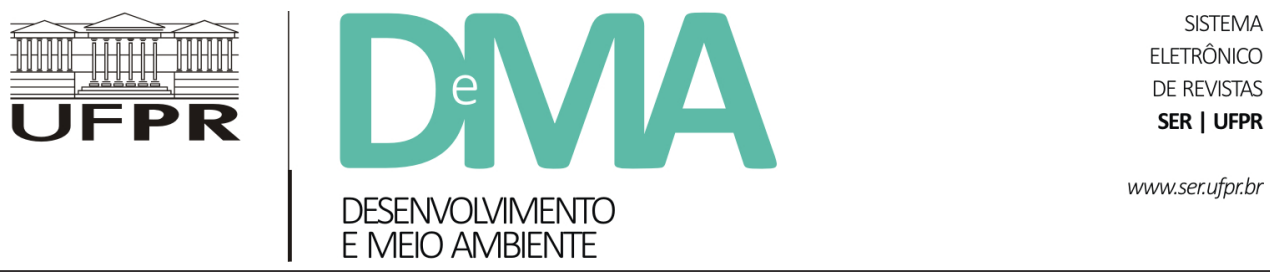

\title{
Priorização de municípios para prevenção, monitoramento e controle de desmatamento na Amazônia: uma contribuição à avaliação do Plano de Ação para a Prevenção e Controle do Desmatamento na Amazônia Legal (PPCDAm)
}

\section{Prioritization of Municipalities for the Prevention, Monitoring and Control of Deforestation in the Amazon: A Contribution to the Assessment of the Action Plan for Prevention and Control of Deforestation in the Brazilian Amazon (PPCDAm)}

Eduardo $\mathrm{BIZZO}^{1 *}$, André Luís Assunção de FARIAS ${ }^{2}$

${ }^{1}$ Banco Nacional de Desenvolvimento Econômico e Social (BNDES), Brasília, DF, Brasil. Este artigo é de exclusiva responsabilidade dos autores, não refletindo, necessariamente, a opinião do BNDES.

${ }^{2}$ Universidade Federal do Pará (UFPA), Belém, PA, Brasil.

*E-mail de contato: ebizzo@gmail.com

Artigo recebido em 28 de junho de 2017, versão final aceita em 13 de novembro de 2017.

RESUMO: Após mais de uma década de redução do desmatamento na Amazônia - relacionada a um conjunto de esforços públicos e da sociedade, destacando-se o Plano de Ação para Prevenção e Controle do Desmatamento na Amazônia Legal (PPCDAm) - esta trajetória passa a apresentar sinais de crescimento. Assim, é importante avaliar os resultados das políticas públicas responsáveis pela redução do desmatamento, permitindo focalizar e adaptar aquelas que lograram êxito. Umas das políticas relevantes no âmbito do PPCDAm, que trouxe implicações para a gestão ambiental compartilhada, é a priorização de municípios para focalização de ações relativas à prevenção, monitoramento e controle de desmatamento no Bioma Amazônia, instituída pelo Decreto $\mathrm{N}^{\mathrm{O}}$ 6.321/2007. O presente trabalho, de caráter interdisciplinar, busca avaliar os resultados desta política. Foi realizada pesquisa de caráter qualitativo e quantitativo abrangendo (i) pesquisa bibliográfica em documentos oficiais e literatura disponível e (ii) análise do desmatamento municipal. Verificou-se que a política teve resultados mais significativos na redução do desmatamento nos seus primeiros anos, tendo influenciado a criação de políticas de regularização ambiental e de incentivo à governança ambiental local. Entretanto, com o passar dos anos, a política deixa de apresentar eficácia. Este desempenho parece relacionarse com a redução das ações executadas e com a demora na atualização da lista de municípios priorizados. O atual contexto demanda um esforço de reformulação da política. A atualização da lista em 2017 traz 
perspectivas positivas, podendo denotar um esforço de se retomar a execução da política, com a revisão dos seus incentivos e aumento de sua efetividade.

Palavras-chave: desmatamento; Amazônia; priorização de municípios; avaliação de políticas públicas; gestão ambiental municipal.

ABSTRACT: After more than a decade of deforestation reduction in the Amazon - in association with a set of government and society efforts, especially the Action Plan for Prevention and Control of Deforestation in the Brazilian Amazon (PPCDAm) - this trajectory has been presenting signs of growth. Therefore, it is important to assess the results of the public policies responsible for the reduction in deforestation, in order to focus on and adapt those that have succeeded. One of the relevant PPCDAm policies, which had an impact on shared environmental management, is the prioritization of municipalities for the focus of actions on the prevention, monitoring and control of deforestation in the Amazon Biome (Decree No. 6,321/2007). This paper aims to assess, from an interdisciplinary perspective, the results of this policy since its creation. Qualitative and quantitative research was carried out, covering (i) bibliographic research based on official documents and available literature and (ii) analysis of municipal deforestation data. The study found that the policy showed more significant results in its early years, having influenced the creation of other policies and, afterwards, presenting a reduction in its effectiveness. This performance seems to be related to the reduction in actions and to the delay in updating the list of prioritized municipalities. Thus, the current context demands an effort to reformulate the policy. The updating of the list in 2017 brings positive perspectives, and may signalize an effort to continue enforcing its execution by revising incentives and increasing its effectiveness.

Keywords: deforestation; Amazon; prioritization of municipalities; policy assessment; municipal environmental management.

\section{Introdução}

Maior floresta tropical do planeta em extensão, a Amazônia possui uma área de aproximadamente 7 milhões de $\mathrm{Km}^{2}$, detém $20 \%$ da água doce da Terra e representa $1 / 3$ das florestas tropicais do mundo (Becker, 2005). A floresta Amazônica está distribuída entre nove países, com cerca de $60 \%$ de sua área no Brasil (INPE, 2017a).

É considerada a região de maior biodiversidade do planeta e lócus de interação de uma diversidade social complexa. Por exemplo, das categorias sociais da produção rural, a região comporta desde povos indígenas de comércio esporádico a latifúndios recentes e exploradores itinerantes (Albagli, 2001; Lima \& Pozzobon, 2005).
O sistema ecológico amazônico permite a provisão de uma série de serviços ambientais à sociedade, dentre eles: (i) Fixação de carbono, manutenção das fontes de água, proteção e fertilização dos solos, regulação da temperatura e do clima; (ii) Oferecimento de valores científicos, culturais, estéticos, dentre outros valores universalmente reconhecidos, mesmo sendo intangíveis e não monetários; (iii) Fonte de alimentos, de produtos farmacêuticos e químicos e de informações para o desenvolvimento da biotecnologia; (iv) Base para as culturas agrícolas e para o melhoramento e desenvolvimento de novas variedades agrícolas (OCDE, 1996).

Todavia, o funcionamento do sistema ecológico amazônico é ameaçado pelo avanço do 
desmatamento. Segundo o Ministério de Meio Ambiente - MMA (2016), até 2014, a área desmatada na Amazônia correspondia a $15 \%$ da sua cobertura florestal original.

Dentre os principais fatores historicamente indutores do desmatamento na Amazônia, estariam: (i) o modelo de colonização baseado na migração e com incentivos ao agronegócio; (ii) a incerteza fundiária e falta de definição de propriedades; (iii) a exploração agropecuária e os investimentos em infraestrutura, principalmente abertura de estrada e pavimentação (Schmitt \& Scardua, 2015).

Contudo, desde 2004, é possível observar uma trajetória descendente na taxa de desmatamento da Amazônia, apesar de um aparente viés de crescimento nos últimos anos, conforme Figura 1.
A redução do desmatamento observada desde 2004, de mais de 70\%, estaria relacionada a diversas iniciativas, articuladas principalmente em nível federal (Cunha et al., 2016). Assunção et al. (2012) afirmam que há dois importantes pontos de inflexão na trajetória do desmatamento: um em 2004 e outro em 2008.

Em 2004, foi instituído o Plano de Ação para a Prevenção e Controle do Desmatamento na Amazônia Legal (PPCDAm), envolvendo iniciativas de 13 Ministérios. Este Plano, que hoje está em sua quarta fase, possui o objetivo de "promover a redução das taxas de desmatamento na Amazônia brasileira, por meio de um conjunto de ações integradas de ordenamento territorial e fundiário, monitoramento e controle, fomento a atividades produtivas sustentáveis

\section{Taxas Prodes - Amazônia Legal (km2)}

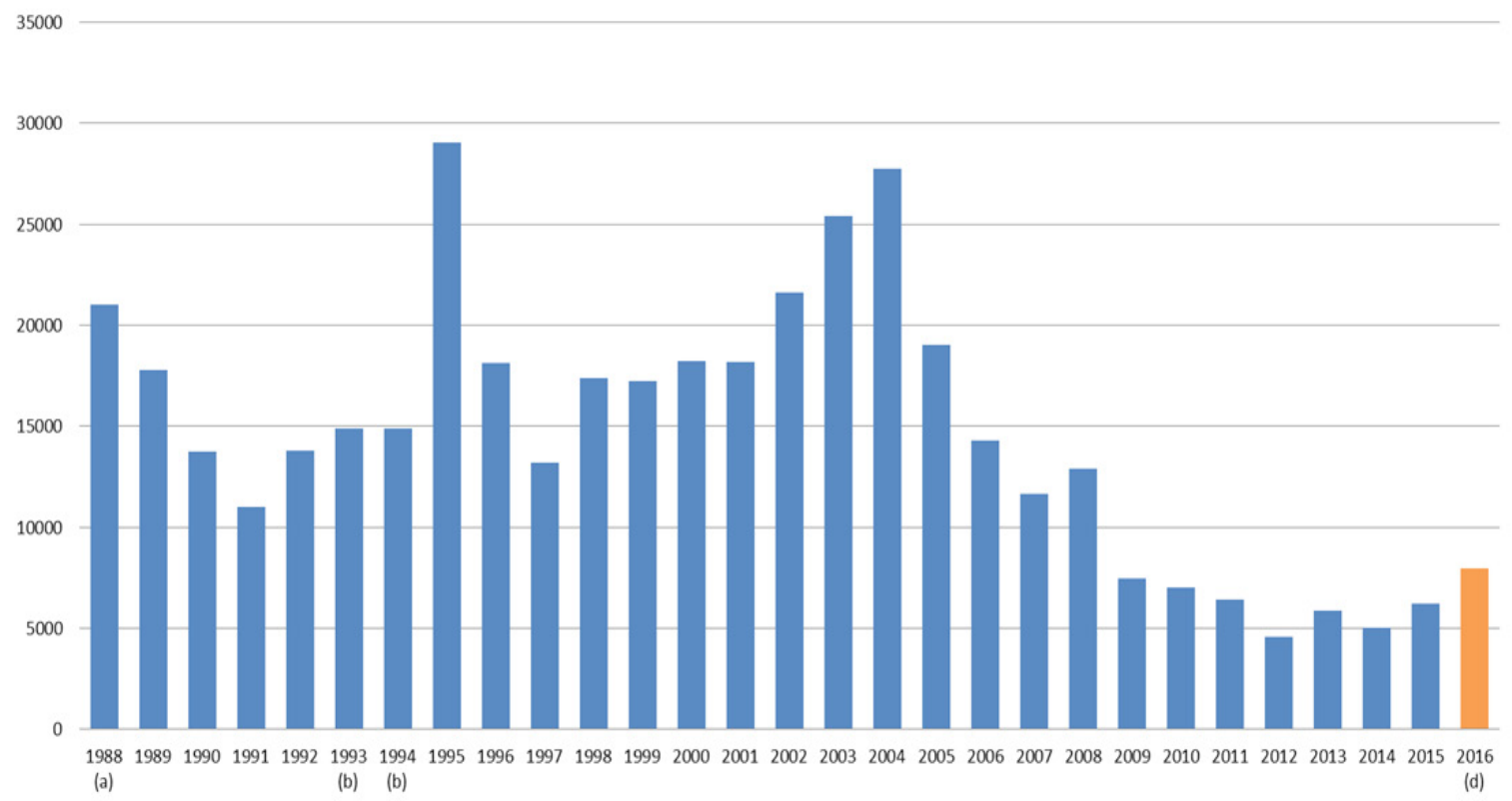

FIGURA 1 - Evolução do desmatamento na Amazônia. (a) Média entre 1977 e 1988, (b) Média entre 1993 e 1994, (d) estimativa. FONTE: INPE (2017b) 
e infraestrutura, envolvendo parcerias entre órgãos federais, governos estaduais, prefeituras, entidades da sociedade civil e o setor privado"(Ministério do Meio Ambiente, 2013).

Assunção et al. (2012) destacam, no âmbito do PPCDAm a partir de 2004, a atuação integrada em monitoramento e controle em conjunto entre Instituto Nacional de Pesquisa Espacial (INPE), Instituto Brasileiro do Meio Ambiente e dos Recursos Naturais Renováveis (IBAMA), Polícia Federal, a Polícia Rodoviária e o Exército Brasileiro, subsidiada com o incremento de capacidade de monitoramento atribuída à implantação do Sistema de Detecção de Desmatamento em Tempo Real (DETER) do INPE. Além disso, apresentam como fator importante a criação de unidades de conservação e o reconhecimento de terras indígenas.

A partir de 2008, os autores destacam: (i) o restabelecimento das diretrizes relativas aos processos administrativos federais para investigar as infrações ambientais e suas respectivas sanções, por meio do Decreto 6.514/2008; (ii) as novas políticas de crédito, por meio da Resolução 3.545 do Conselho Monetário Nacional, determinando que o crédito rural para atividades agropecuárias no Bioma Amazônia fosse condicionado à apresentação de comprovação de conformidade com a legislação ambiental e legitimidade do título de terra do mutuário; e, principalmente, (iii) a política de priorização de municípios para focalização de ações relativas à prevenção, monitoramento e controle de desmatamento no Bioma Amazônia, instituída pelo Decreto $N^{\circ} 6.321 / 2007$.

Com esta política, estabelecida no âmbito do PPCDAm, a priorização de municípios passa a ser uma orientação estratégica para o combate ao desmatamento em nível local, trazendo impli- cações para a gestão ambiental compartilhada. É importante mencionar que os governos municipais vêm ampliando, nas últimas décadas, sua atuação no tocante à gestão ambiental: competência compartilhada entre todos os entes federados, com responsabilidades expressas na Constituição Federal Brasileira e na Politica Nacional do Meio Ambiente (Carvalho et al., 2005; Leme, 2011).

Após uma década de trajetória decrescente no desmatamento, as taxas demonstram tendência de crescimento em um ambiente de redução de orçamento público disponível para ações de fiscalização e controle e um congresso mais favorável ao agronegócio (Fearnside, 2015). Neste contexto, faz-se importante avaliar os resultados das ações públicas responsáveis pela redução do desmatamento no sentido de focalizar e adaptar aquelas que lograram êxito, particularmente o critério de priorização dos municípios.

Assim, o presente trabalho problematiza a priorização de municípios para focalização de ações relativas à prevenção, monitoramento e controle de desmatamento na Amazônia, tendo por objetivo principal a avaliação dos resultados desta política.

A hipótese que orienta a pesquisa considera que os seus principais resultados positivos - dados pela redução proporcional do desmatamento nos municípios prioritários - foram alcançados nos primeiros anos da política, mas, com o passar dos anos, suas ações deixaram de ser realizadas, implicando no aumento do desmatamento nos mesmos municípios.

O trabalho é de caráter interdisciplinar, se insere na literatura de avaliação de políticas públicas e contribui com a avaliação de resultados da mencionada política, uma vez que as análises existentes não reúnem os diferentes resultados específicos e estão 
limitados aos primeiros anos da política (Arima et al., 2014; Assunção \& Rocha, 2014).

Para tal, está organizado em três seções, além da introdução e considerações finais. A primeira apresenta a abordagem teórica da avaliação de políticas públicas e os procedimentos metodológicos empregados no estudo. A segunda caracteriza a política de combate ao desmatamento, destacando a escolha dos municípios prioritários. Finalmente, a terceira seção avalia os principais resultados da aplicação da política.

\section{Avaliação de políticas públicas: um guia teórico-metodológico necessário para a gestão ambiental}

\subsection{Avaliação de Políticas Públicas}

As políticas públicas configuram um conjunto de procedimentos formais e informais que se referem às relações de poder tendo como objetivo a resolução pacífica dos conflitos quanto a bens públicos (Rua, 1997). É por meio das políticas públicas que os governos materializam seus propósitos em programas e ações para produzir os resultados ou as mudanças desejadas no mundo real (Souza, 2003).

O ciclo das políticas - processo deliberativo não-linear de fases sequenciais e interativas-iterativas no processo político - é composto pelas seguintes etapas: (i) formação da agenda, quando um problema político é identificado e discutido pelos tomadores de decisão (ii) formação das alternativas, formulação da política e tomada de decisão; (iii) implementação; e (iv) avaliação (Souza, 2003; Jann \& Wegrich, 2007; Rua, 2009).
Última etapa do ciclo das políticas, a avaliação é destinada a apreciar os resultados e fornecer elementos para o desenho de novas intervenções ou para o aprimoramento de políticas e programas em curso (Faria, 2005). A partir da avaliação seria possível identificar e incentivar os programas que funcionam com mais efetividade, eficácia e eficiência, bem como orientar aqueles com fraco desempenho no sentido de seu aperfeiçoamento (Fagundes \& Moura, 2009; Ramos \& Schabbach, 2012).

A avaliação permite a melhoria da eficiência do gasto público, da qualidade da gestão e do controle social sobre a efetividade da ação do Estado, além de auxiliar os formuladores e gestores de políticas públicas para desenharem políticas mais consistentes, com melhores resultados e melhor utilização dos recursos (Ramos \& Schabbach, 2012). Apesar do padrão brasileiro ser o da tomada de decisões sobre programas e políticas sem seu adequado conhecimento, há no País um crescente interesse dos governos na avaliação (Fagundes \& Moura, 2009; Ramos \& Schabbach, 2012).

É possível classificar as avaliações com respeito aos tipos de problema ou pergunta: avaliação de processos, realizada durante a implementação, diz respeito à gestão e ao suporte para melhorar a eficiência operativa; e avaliação de impactos ou resultados, com objetivos mais ambiciosos sobre os efeitos diretos e impactos das políticas (Cunha, 2006).

Conforme Ramos \& Schabbach (2012), a avaliação de resultados verifica em que medida o programa alcançou os objetivos e quais foram seus efeitos e consequências, se houve modificações na situação-problema que originou a formulação do programa e mudança efetiva nas condições prévias de vida das populações beneficiadas, enquanto a 
avaliação de impacto verifica a existência de um nexo causal entre os resultados da implantação do programa ou projeto e as alterações nas condições sociais da população no longo prazo.

Conforme Bauer (2010), na vasta literatura sobre avaliação são utilizados diferentes conceitos e muitas vezes não há diferenciação entre resultado e impacto. Em linhas gerais, impactos são entendidos como resultados e efeitos da intervenção a longo termo, que são mantidos mesmo após o término da intervenção e com a utilização de um contrafactual para isolar apenas os efeitos das políticas. Para o autor, há uma questão política no uso terminológico, pois o termo "impacto" poderia implicar uma conotação mais forte e robusta quando comparado ao termo "resultado".

Ciente deste debate, considerando que a política continua vigente (Decreto está em vigor e a política é mencionada na quarta fase do PPCDAm, de 2016) e que não há avaliação de resultados para os anos posteriores, o estudo pretende realizar uma avaliação de resultados da política.

\subsection{Recorte territorial}

A pesquisa focaliza os 52 municípios que já foram objetos da política de priorização de municípios para ações relativas à prevenção, monitoramento e controle de desmatamento no Bioma Amazônia até 2016 - último ano com disponibilidade de dados de desmatamento municipais até a data de publicação deste artigo- e realiza comparação com os demais municípios da Amazônia Legal ${ }^{1}$.
A maioria dos municípios listados está localizada na região denominada "Arco do desmatamento", área de expansão de fronteira agrícola sobre a floresta e que concentra os maiores índices de desmatamento da Amazônia. O Arco abrange municípios que se estendem do sudeste do estado do Maranhão ao norte do Tocantins, sul do Pará, norte de Mato Grosso, Rondônia, sul do Amazonas e sudeste do estado do Acre (Ferreira et al., 2005).

A região é espaço de interação entre atores sociais e interesses complexos, que tornam a fronteira um lugar de encontro, de oportunidades, de capitalização, bem como de tensão e de conflito (Castro, 2008). Por ser uma região de confluência das múltiplas pressões do desmatamento, por responder pela maior parte do desmatamento da Amazônia e por configurar como zona de fronteira, ou seja, de abertura para o desmatamento no centro da Amazônia, o recorte de municípios estudados possui grande relevância no tema da conservação ambiental.

Embora a priorização de municípios para ações relativas à prevenção, monitoramento e controle de desmatamento na Amazônia seja uma política conduzida pelo Governo Federal, ao incentivar e punir municípios traz implicações para a gestão ambiental local. Neste sentido, ao focalizar em uma política conduzida pelo Governo Federal mas com impactos nos municípios, a pesquisa traz contribuições à literatura sobre gestão ambiental compartilhada. Os municípios da lista estão dispostos na Tabela.

A localização dos municípios abrangidos pela política é representada no mapa pela Figura 1.

\footnotetext{
${ }^{1}$ A Amazônia Legal é uma divisão político-administrativa correspondente ao Acre, Amapá, Amazonas, Pará, Rondônia, Roraima, Tocantins, Mato Grosso e os municípios do Estado do Maranhão situados a oeste do meridiano $44^{\circ} \mathrm{O}$.
} 


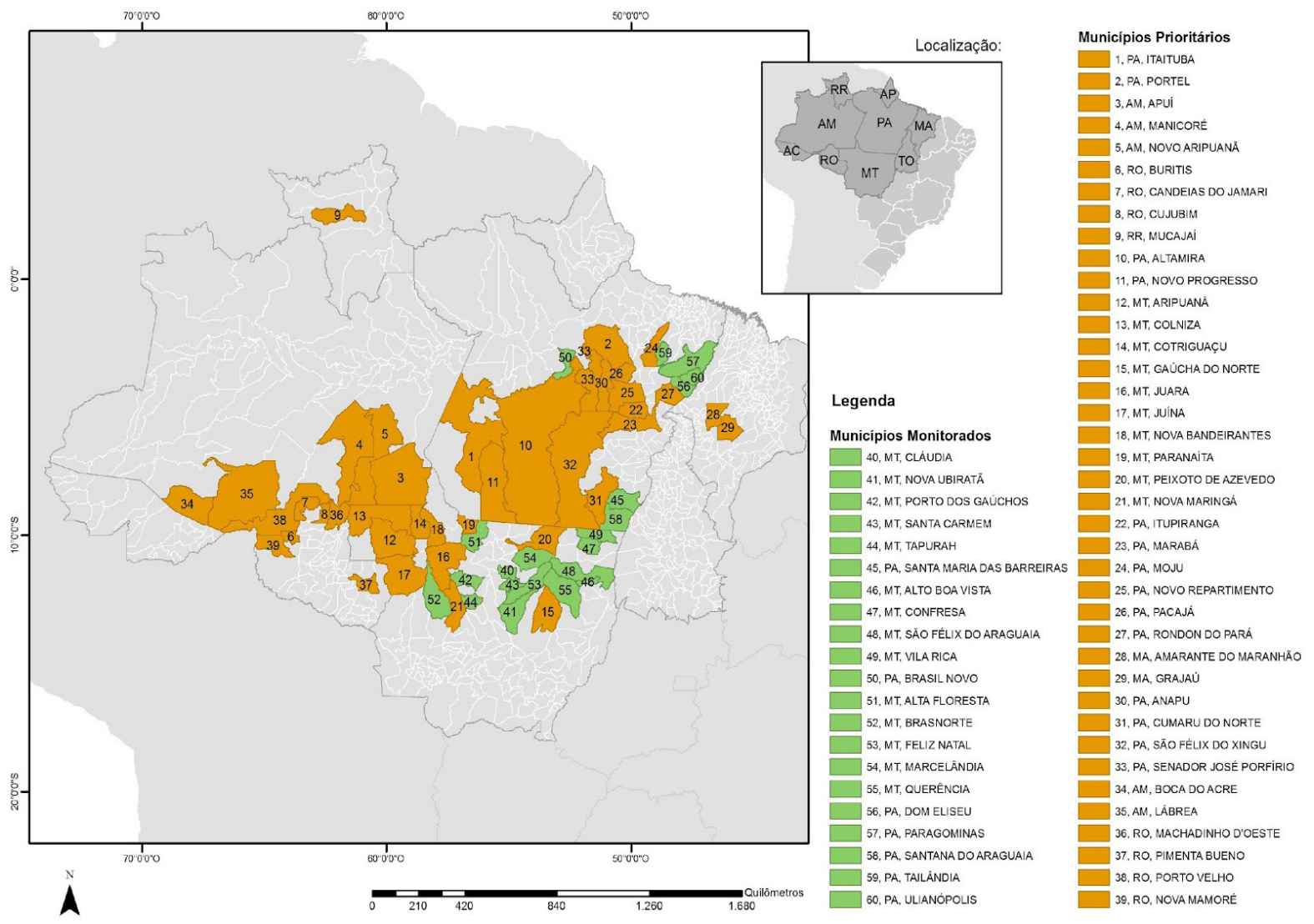

FIGURA 1 - Mapa de municípios abrangidos pela política de priorização.

FONTE: Ministério do Meio Ambiente - MMA (2017).

TABELA 1 - Lista de municípios abrangidos.

\begin{tabular}{cccc}
\hline $\begin{array}{c}\text { Ano de Entrada } \\
\text { na Lista }\end{array}$ & $\begin{array}{c}\text { Ano de Saída da } \\
\text { Lista }\end{array}$ & Município & Estado \\
\hline 2008 & - & Lábrea & AM \\
2008 & - & Aripuanã & MT \\
2008 & - & Colniza & MT \\
2008 & 2017 & Confresa & MT \\
2008 & - & Cotriguaçu & MT \\
2008 & - & Gaúcha do Norte & MT
\end{tabular}




\begin{tabular}{|c|c|c|c|}
\hline 2008 & - & Juína & MT \\
\hline 2008 & - & Nova Bandeirantes & MT \\
\hline 2008 & 2017 & Nova Ubiratã & MT \\
\hline 2008 & - & Paranaíta & MT \\
\hline 2008 & - & Peixoto de Azevedo & MT \\
\hline 2008 & 2017 & Porto dos Gaúchos & 1 \\
\hline 2008 & 2017 & São Félix do Araguaia & IT \\
\hline 2008 & 2017 & Vila Rica & MT \\
\hline 2008 & - & Nova Maringá & ИT \\
\hline 2008 & 2011 & Querência & IT \\
\hline 2008 & 2012 & Alta Floresta & IT \\
\hline 2008 & 2013 & Brasnorte & \\
\hline 2008 & 2013 & Marcelândia & \\
\hline 2008 & - & Altamira & \\
\hline 2008 & - & Cumaru do Norte & PA \\
\hline 2008 & - & Novo Progresso & PA \\
\hline 2008 & - & Novo Repartimento & PA \\
\hline 2008 & - & Rondon do Pará & A \\
\hline 2008 & 2017 & Santa Maria das Barreiras & \\
\hline 2008 & - & São Félix do Xingu & \\
\hline 2008 & 2010 & Paragominas & PA \\
\hline 2008 & 2012 & Dom Eliseu & PA \\
\hline 2008 & 2012 & Santana do Araguaia & PA \\
\hline 2008 & 2012 & Ulianópolis & PA \\
\hline 2008 & 2013 & Brasil Novo & A \\
\hline 2008 & - & Machadinho D'Oeste & U \\
\hline 2008 & - & Pimenta Bueno & $\mathrm{R}$ \\
\hline 2008 & - & Porto Velho & $\mathrm{O}$ \\
\hline 2008 & - & Nova Mamoré & RO \\
\hline 2009 & - & Amarante do Maranhão & \\
\hline 2009 & - & Juara & MT \\
\hline 2009 & 2013 & Feliz Natal & 11 \\
\hline 2009 & - & Itupiranga & A \\
\hline 2009 & - & Marabá & $\mathrm{A}$ \\
\hline 2009 & - & Pacajá & $\mathrm{A}$ \\
\hline 2009 & 2013 & Tailândia & A \\
\hline 2009 & - & Mucajaí & \\
\hline
\end{tabular}




\begin{tabular}{lccc}
\hline & & & \\
2011 & - & Boca do Acre & AM \\
2011 & - & Grajaú & MA \\
2011 & 2017 & Alto Boa Vista & MT \\
2011 & 2017 & Cláudia & MT \\
2011 & 2017 & Santa Carmem & MT \\
2011 & 2017 & Tapurah & MT \\
2011 & - & Moju & PA \\
2012 & - & Anapu & PA \\
2012 & - & Senador José Porfírio & PA \\
2017 & - & Apú́ & AM \\
2017 & - & Manicoré & AM \\
2017 & - & Nova Aripuanã & AM \\
2017 & - & Itaituba & PA \\
2017 & - & Portel & PA \\
2017 & - & Buritis & RO \\
2017 & - & Candeias do Jamari & RO \\
2017 & - & Cujubim & RO \\
\hline
\end{tabular}

FONTE: Elaboração própria

\subsection{A redução do desmatamento como} resultado esperado da política de priorização de municípios

O principal resultado direto esperado com a priorização de municípios da Amazônia é a redução do desmatamento. Para a análise do desmatamento municipal, foram utilizados os dados anuais por município divulgados pelo Projeto de Monitoramento do Desmatamento na Amazônia Legal por Satélite (PRODES) do INPE de 2005 a 2016. Os dados dos 52 municípios que já integraram a lista em algum momento até então são comparados com os da Amazônia Legal. Conforme base municipal do PRODES de 2016, são considerados um total de 760 municípios (inclusive os 52 da lista).
O programa, de referência internacional, divulga dados de perda de floresta primária por meio do mapeamento da dinâmica do desmatamento por Corte Raso (aquele que resulta na remoção completa da cobertura florestal em um curto intervalo de tempo e substituída por outras coberturas e usos, como agrícola, pastagem, urbano, hidroelétricas) com uso de imagens dos satélites.

Anualmente, é possível consultar pelo PRODES os dados, por $\mathrm{Km}^{2}$, de todos os municípios da Amazônia legal, relativos ao total desmatado, ao incremento do desmatamento do ano, às classes de cobertura da terra (floresta, não floresta, hidrografia), às nuvens e às áreas não observadas. Até a data de conclusão do trabalho, os dados municipais de desmatamento estavam disponíveis até o ano de 
2016. O estudo considerou, a cada ano, o incremento do desmatamento municipal.

\section{Caracterização da política de prevenção e combate ao desmatamento: priorização de municípios como instrumento de gestão ambiental}

\subsection{A Política de prevenção e combate ao desmatamento e a priorização de municípios}

Com o avanço do problema do desmatamento, com consequentes impactos negativos de diversas naturezas, somada à propagação da temática ambiental nas políticas públicas, governos nacionais e subnacionais em diversos países nos últimos vinte anos vêm adotando políticas para preservação e uso sustentável das florestas (Boucher et al., 2014). No Brasil, as primeiras políticas relacionadas à conservação florestal, com objetivos mais relacionados à garantia de oferta madeireira, remontam ao período colonial (Medeiros, 2006).

Conforme Bacha (2004), a década de 30 presenciou o primeiro conjunto amplo de medidas relacionadas à proteção e à limitação de uso de recursos naturais, com a criação de códigos, como o Código Florestal de 1934. Já no período de 1965 a 1988 se dá o recrudescimento de medidas de comando e controle do desmatamento, sem criar estímulos econômicos à conservação florestal.

Para o autor, o período pós 1988 teria trazido uma ênfase em medidas de proteção, enfocando a disciplina do desmatamento em termos de unidades produtivas. Destaca-se a definição de uma política global para o meio ambiente, o aperfeiçoamento da legislação florestal, a obrigatoriedade do Relatório de Impacto Ambiental em empreendimento de impacto significativo, o fim de incentivos fiscais para projetos agropecuários que levassem ao desmatamento na Amazônia e a ampliação da reserva legal. Entretanto, as medidas não teriam logrado êxito no controle do desmatamento.

É com o PPCDAm em 2004 que a questão da prevenção e controle do desmatamento eleva-se ao mais alto nível da agenda política do Governo Federal para a Amazônia, sendo tema atual e recorrente em vários programas, planos e projetos governamentais (Maia et al., 2011). Neste bojo, uma série de esforços públicos - como aumento do comando-e-controle, melhoria do monitoramento, expansão de áreas protegidas e restrição de crédito - bem como intervenções na cadeia de valor da pecuária e da soja, com participação do Ministério Público, terceiro setor e setor privado, contribuíram para uma redução significativa do desmatamento após 2004 (Nepstad, 2014).

Uma das iniciativas relevantes neste conjunto, no âmbito do PPCDAm, é a política de priorização de municípios para ações relativas à prevenção, monitoramento e controle de desmatamento no Bioma Amazônia. Instituída pelo Decreto $N^{\circ}$ 6.321, de 21 de dezembro de 2007, determinou a edição periódica, pelo Ministério do Meio Ambiente, de portaria com a lista de municípios identificados como principais responsáveis pelo desmatamento na região e, consequentemente, que deveriam ser priorizados em políticas relacionadas à redução do desmatamento.

Pelo Decreto, os imóveis rurais situados nos municípios listados devem realizar atualização cadastral junto ao Instituto Nacional de Colonização e Reforma Agrária (INCRA), com objetivo de reu- 
nir dados e informações para monitorar, de forma preventiva, a ocorrência de novos desmatamentos ilegais, bem como promover a integração de elementos de controle e gestão compartilhada entre as políticas agrária, agrícola e ambiental.

O Decreto prevê também a proibição de crédito oriundo de agências oficiais federais para atividade agropecuária e florestal realizada em imóveis rurais que descumprissem o embargo de atividade relacionado a desmatamento e queimada irregulares e para serviço, atividade comercial ou industrial que adquirisse, intermediasse, transportasse ou comercializasse produto ou subproduto de origem animal ou vegetal produzido sobre área de embargo. Para a formação da lista, o Ministério de Meio Ambiente consideraria os seguintes critérios tendo por base a série histórica de desmatamento verificada pelo INPE: I - área total de floresta desmatada; II - área total de floresta desmatada nos últimos três anos; e III - aumento da taxa de desmatamento em pelo menos três, dos últimos cinco anos.

Por outro lado, para sair da lista, sendo considerado um município com "desmatamento monitorado e sob controle" devem ser cumpridos, cumulativamente, os seguintes requisitos: I - possuir $80 \%$ de seu território, excetuadas as unidades de conservação de domínio público e terras indígenas homologadas, com imóveis rurais devidamente monitorados na forma e de acordo com critérios técnicos fixados em instrução normativa específica do INCRA; II -manter taxa de desmatamento anual abaixo do limite estabelecido em portaria do Ministério do Meio Ambiente.

$\mathrm{Na}$ primeira lista, formalizada pela Portaria MMA n ${ }^{\circ} 28 / 2008$, constavam 35 municípios. Em 2009, por meio da Portaria MMA n ${ }^{\circ} 102 / 2009$, foram adicionados mais 8 municípios e, em 2010, com a Portaria MMA n ${ }^{\circ}$ 67/2010, foi retirado da lista o município de Paragominas - PA. Em 2011, com a Portaria MMA no 139/2011, foi retirado município de Querência - MT e, com a Portaria MMA n ${ }^{\circ}$ 175/2011, incluídos mais 7 municípios. Em 2012, 4 municípios foram excluídos da lista (portarias MMA n $^{\circ} 187 / 2012$ e 324/2012) e ingressaram mais 2 municípios (Portaria MMA no 323/2012). Em 2013, foram excluídos 2 municípios (Portaria MMA $n^{\circ}$ 412/2013). Finalmente, em 2017 (Portaria n 361 e 362/2017) oito foram incluídos e 10 retirados da lista.

A quarta fase do PPCDAm, lançada em dezembro de 2016, dispõe que será mantida a edição periódica da lista de municípios prioritários conforme Decreto $^{\circ}{ }^{\circ} 6.321 / 2007$, mas com aprimoramento de sua metodologia e seu escopo de atuação (Ministério do Meio Ambiente, 2016). Conforme o Plano, de modo aderente à Operação Arco Verde de 2008, como abordado na próxima seção, a iniciativa não será restrita ao viés da repressão e da punibilidade, mas buscará uma agenda positiva para a redução do desmatamento.

Embora tenha havido um período de não atualização da lista, de 2013 a 2017, que pode ter, em alguma medida, contribuído para a inflexão na curva do desmatamento, sua revisão pode ser vista com boas perspectivas. Ela pode denotar um esforço do Ministério do Meio Ambiente de retomar a execução da política, com a revisão dos incentivos de premiação e punição, que podem aumentar sua efetividade.

\subsection{Principais ações realizadas}

Ao entrarem na lista, os municípios sofreram 
sanções econômicas como a restrição de crédito rural, ações estratégicas de fiscalização e controle com maior frequência, embargo de propriedades rurais e responsabilização da cadeia produtiva, resultando na perda de empregos e redução da arrecadação tributária (Sousa Jr. et al., 2013).

Em 2008, conforme Ministério do Meio Ambiente (2013), foram iniciadas, nos municípios listados, operações intensivas coordenadas pela Polícia Federal, com apoio do IBAMA e Força Nacional de Segurança, destinadas a coibir ilegalidades relacionadas ao desmatamento e ao comércio irregular de produtos madeireiros. A atuação ficou conhecida como Operação Arco do Fogo.

Conforme Ministério do Meio Ambiente - MMA (2016), na avaliação da terceira fase do PPCDAm (2012 a 2015), a região do arco do desmatamento, onde está localizada a maioria dos municípios, continua sendo foco para ações de fiscalização do IBAMA e do Centro Gestor e Operacional do Sistema de Proteção da Amazônia (Censipam). Entretanto, não estão especificadas no documento as ações priorizadas nos municípios.

Adicionalmente, em contraposição às medidas de repressão e visando à promoção de sistemas sustentáveis, foi instituída a Operação Arco Verde (OAV) em 2008. Inicialmente, houve a criação de linhas de crédito de fundos constitucionais para projeto de restauração florestal e produção sustentável e, em 2009, a operação foi intensificada com a realização de mutirões nos municípios, com presença de órgãos dos diferentes níveis de governo, para planejamento e geração de compromissos institucionais, incluindo atividades de regularização fundiária, capacitações e formulação de pactos locais (Maia et al., 2011; MMA, 2013).
Para acompanhar os compromissos pactuados, foi criado o Comitê Gestor Nacional da Operação Arco Verde (art. $6^{\circ}$ do Decreto $N^{0}$ 7.008/2009), formado pela Casa Civil, também responsável por sua coordenação, Ministério do Meio Ambiente, Ministério da Agricultura, Pecuária e Abastecimento e então Ministério do Desenvolvimento Agrário. O Comitê seria responsável por elaborar relatórios quadrimestrais sobre a implementação da Operação Arco Verde. Entretanto, tais relatórios não estão disponíveis em sites oficiais. A falta de transparência em relação aos dados oficiais cria grande dificuldade para a pesquisa científica, em particular àquelas que poderiam auxiliar a avaliação de políticas públicas.

Foi solicitado à Casa Civil, por meio do Sistema Eletrônico do Serviço de Informação ao Cidadão - E-SIC do Governo Federal acesso aos relatórios quadrimestrais do Comitê Gestor Nacional e ao número de reuniões realizadas. $\mathrm{O}$ pedido foi repassado ao Ministério do Meio Ambiente, que respondeu prontamente, dentro do prazo de 20 dias estipulado pela Lei de Acesso à Informação ( $§ 1^{\circ}$, Art. 10 da Lei $N^{o} 12.527$, de 18 de novembro de 2011).

Conforme a resposta, há registro da realização de cinco reuniões do Conselho Gestor Nacional em 2010 e 2011, duas em 2010 e três em 2011. Destas, há relatórios de quatro das cinco reuniões. Comparativamente, percebe-se maior densidade nas discussões no primeiro ano. Como um indicador, as atas de 2010 possuem 1.500 palavras enquanto as de 2011 possuem apenas 450 . O número de reuniões reforça que a política foi relevante em um primeiro momento, mas que sua implementação foi reduzida, uma vez que as últimas reuniões do conselho gestor que integra a política foi em 2011 e que, mesmo neste ano, as discussões foram menos densas. 
Conforme Relatório de situação de 2010, também enviado na resposta ao pedido de acesso, estiveram entre os resultados da OAV a priorização da regularização fundiária por meio do Programa Terra Legal Amazônia; a criação do PRONAF Sustentável para a agricultura familiar; a criação do Cartão Verde para os Assentamentos da Reforma Agrária; a decisão de deixar de criar Projetos de Assentamentos tradicionais na Amazônia; a instalação de quinze agências da Previdência Social nos municípios participantes da Operação; a doação aos municípios de patrulhas agrícolas; a contratação de 1.450 brigadistas para o combate às queimadas; a realização de capacitações para o fortalecimento da gestão ambiental municipal; o desenvolvimento de novas tecnologias e o aprimoramento das linhas de crédito para a recuperação de áreas degradadas por meio de sistemas agroflorestais.

Além disso, consta na ata da reunião do Conselho Gestor de outubro de 2011 que este propôs a adoção de duas estratégias principais para atingir o objetivo de redução do desmatamento com estímulo e fomento a alternativas produtivas sustentáveis: (i) a priorização pelos órgãos públicos federais da implementação das Agendas de Compromissos elaboradas por ocasião dos Mutirões Arco Verde - Terra Legal e (ii) a identificação, elaboração de planos de trabalho e a promoção de atividades estratégica para a Produção Sustentável.

Conforme expõe Neves (2016), embora houvesse expectativa de que o OAV trouxesse contribuições estruturantes para a transição para sistemas produtivos sustentáveis, isto não aconteceu. Ainda não há estudos relevantes publicados com os resultados da Operação Arco Verde.
3.3. Relação entre a política de prevenção

e combate ao desmatamento, priorização

dos municípios e gestão ambiental

compartilhada.

No Brasil, conforme art. 23 da Constituição Federal de 1988, o tema ambiental é competência comum de todos os Entes Federados. A definição de atribuições e responsabilidades entre os entes federativos é dada pela Lei Complementar No 140/2011. A Política Nacional do Meio Ambiente, instituída pela Lei $\mathrm{N}^{\circ} 6.938 / 1981$, inclui os órgãos locais responsáveis pela proteção e melhoria da qualidade ambiental como componentes do Sistema Nacional do Meio Ambiente - SISNAMA.

Conforme ScarduaI \& Bursztyn (2003), a Constituição Federal, que possui a descentralização - entendida como a transferência de autoridade e de poder decisório para instâncias subnacionais - como um de seus princípios, elevou os o municípios à condição de unidade federada. Entretanto, trouxe mais obrigações e competências para eles no tema ambiental, mas não aumentou sua capacidade institucional, administrativa e financeira para cumprir essas novas atribuições.

Para Leme (2011), contudo, tem havido um processo de fortalecimento da gestão ambiental municipal no Brasil, com a assunção gradativa de atribuições. A autora identificou a evolução em relação a estrutura, pessoal, conselho e recursos ao se comparar os municípios brasileiros de 2002 a 2008, com destaque para os municípios da região Norte, que demonstraram os maiores percentuais de fortalecimento, entre eles, os do Estado do Tocantins.

Em teoria, a descentralização pode trazer benefícios como o aumento da eficácia e da eficiência 
da ação governamental, aproximando fornecedores e usuários de serviços públicos em uma gestão mais efetiva; a democratização do poder local, com possibilidade de aperfeiçoamento da participação política e a accountability; além de incentivar inovações administrativas (Carlo, 2006).

Além disso, para Leme (2011), há diversos exemplos de iniciativas locais de recuperação, preservação e boa gestão dos recursos naturais, pois, além de permitir soluções criativas locais, no município a população está mais próxima dos representantes políticos e interage diretamente com as políticas públicas. A descentralização possibilitaria que, nesse espaço territorial, a organização da sociedade levasse à construção de consensos e de outras lógicas de desenvolvimento valorizando as questões locais, as relações humanas e a justiça social.

Por outro lado, a descentralização traz riscos como as práticas clientelistas e coronelistas ligadas a questões políticas locais, que podem influenciar a forma de atuação dos órgãos municipais de meio ambiente; a corrupção de políticos e funcionários públicos; a intensificação das desigualdades regionais; e, o exercício do poder local sobre os processos de participação social (Scardua \& Bursztyn, 2003; Carlo, 2006). Estes riscos são agravados por fatores como a deficiência de corpo técnico dos órgãos municipais de meio ambiente, falta de capacitação e treinamento, carência de recursos e infraestrutura, além dos interesses locais comumente focalizarem o crescimento econômico em detrimento das questões ambientais (Scardua \& Bursztyn, 2003; Carlo, 2006)

Para Neves (2012), o federalismo brasileiro enseja uma ação conjunta entre os níveis de governo onde é fundamental a cooperação intergover- namental. A política ambiental traria as seguintes características que demandam grande necessidade de cooperação: o envolvimento simultâneo de diversas instâncias político-administrativas na gestão de processos ambientais; a transversalidade das políticas; a pluralidade de atores e de organizações na arena ambiental; as múltiplas escalas temporais e espaciais dos processos ambientais; e, a tensão entre tendências à centralização e à descentralização da ação estatal. Entretanto, para autora, se tem visto a predominância de práticas não cooperativas, com competição predatória e pela ação compartimentalizada dos entes federados. Esse contexto demanda o estabelecimento de agendas claras e de mecanismos de cooperação entre diferentes de governo para a viabilização de ações ambientais, como a redução do desmatamento.

A política de priorização configura uma iniciativa onde há explicitamente a tentativa do governo federal em sinalizar para os governos municipais que estes devem se engajar nas políticas de redução do desmatamento da Amazônia. Ao entrar na lista, o município se tornaria alvo mais frequente de fiscalização do Governo Federal, sofreria restrições econômicas e teria seu nome "sujo", tendo um impacto negativo sobre sua reputação.

Por um lado, há um incentivo ao engajamento em nível local para não permitir que o desmatamento aumente, evitando que se entre na lista e sofra esses impactos. Por outro, ao entrar na lista, o município tem incentivos para reduzir o desmatamento e diminuir estes efeitos. Sobre o último ponto, Neves (2016) demonstra que municípios que conseguiram sair da lista tiveram que mobilizar localmente políticas, atores, recursos e parcerias no sentido de melhorar a qualidade da governança ambiental 
local, reduzindo o desmatamento e realizando o Cadastro Ambiental Rural (CAR) ${ }^{2}$.

Incentivar o aumento da governança ambiental em nível municipal é particularmente relevante na região do arco do desmatamento, onde estão concentrados os municípios da lista. A região é espaço de conflito e pressões de atores locais que historicamente se beneficiam do crescimento econômico desordenado, como os relacionados a pecuária, soja e especulação fundiária. Atores locais com este perfil nos municípios tendem a ser um risco para descentralização da política ambiental, conforme demonstra a literatura. Logo, é de se esperar que, por conta própria e na ausência de incentivos claros, os governos municipais destes territórios não tenham capacidade de melhoria significativa na governança ambiental. A política, idealmente, parece ter efeito direto sobre esses atores, tanto com o aumento da fiscalização das suas atividades, quanto nas sanções econômicas que prejudicariam esses setores.

Logo, a política apresenta uma iniciativa de fortalecimento da gestão compartilhada, uma vez que incentivaria os governos municipais a atuarem na mesma direção do Governo Federal em termos de políticas de conservação florestal. Aliás, a preocupação do Governo Federal em articular e unir esforços no âmbito da gestão compartilhada torna-se clara ao considerar os mutirões realizados no âmbito da OAV reunindo políticas de diferentes níveis de governo. Todavia, os impactos pretendidos sobre a gestão compartilhada variam com o nível de implementação da política e do alcance dos resultados esperados.

\section{Resultados da implementação da política: avanços, retrocessos e perspectivas diante de uma nova crise do Estado}

\subsection{Resultados e impactos diretos e indiretos da política}

Arima et al. (2014), analisam econometricamente o impacto da política dos municípios prioritários de 2009 a 2011 e verificam que esta foi efetiva na redução do desmatamento. Entretanto, o estudo não apresenta as causas para a redução do desmatamento. Assunção \& Rocha (2014) avaliam que a política também foi efetiva nos municípios, tendo evitado, nos anos de 2008 a 2011, cerca de 11,4 mil $\mathrm{km}^{2}$ de desmatamento, equivalente à metade da área de Sergipe.

Estes autores verificaram que as principais causas da redução foram o aumento da fiscalização e a melhoria da aplicação da lei (fiscalização mais frequente e concentração de esforços do IBAMA, o aumento do rigor nos requerimentos de licenciamento e um maior esforço para identificar fraudes em documentos e ocupações territoriais). Por outro lado, a politica não teria tido impacto significativo nas atividades econômicas e no crédito rural.

Neste sentido, Matos (2016), ao comparar a relação entre o número de autos de infração - documento que inicia o processo administrativo para apuração de infração ambiental - e taxas de desmatamento, demonstra que a maior presença do Estado

\footnotetext{
${ }^{2}$ CAR, conforme Art. 29 da Lei No 12.651, de 25 de maio de 2012 (Código Florestal), é o registro público eletrônico de âmbito nacional, obrigatório para todos os imóveis rurais, com a finalidade de integrar as informações ambientais das propriedades e posses rurais, compondo base de dados para controle, monitoramento, planejamento ambiental e econômico e combate ao desmatamento.
} 
com atividades de fiscalização e controle impacta na redução do desmatamento. Delazeri (2016), ao analisar as causas do desmatamento de 2008 e 2012 nos municípios prioritários, avalia que a atividade pecuária teve um efeito significativamente negativo para a conservação florestal, enquanto a presença de secretarias municipais de meio ambiente teve efeito significativamente positivo e a atividade de soja não teve impacto significativo. A autora não considerou como variável algum componente de especulação fundiária.

Conforme Pires (2013), o critério de possuir $80 \%$ dos imóveis monitorados de acordo com critérios técnicos do Incra, uma das condições para sair da lista, foi substituído pela Portaria $\mathrm{N}^{\circ} \mathrm{MMA}$ 102 de 2009 pela exigência de, no mínimo, 80\% da área cadastrável do município com CAR. No âmbito federal, esta portaria definiu pela primeira vez o que seria CAR. Em seguida, foram implementados projetos de cadastramento em municípios da lista, sendo um importante passo para a consolidação do CAR como instrumento para regularização ambiental dos imóveis rurais em âmbito nacional no Código Florestal (Art. 29 da Lei no 12.651/2012)

Além do CAR, a política contribuiu para a criação de importantes políticas estaduais que visam a melhoria da governança ambiental local. O município de Paragominas no Pará, logo após entrar na lista instituiu um projeto chamado "Paragominas: Município Verde", baseado na realização de um pacto local entre os diferentes atores no município contra o desmatamento, seguida de ações de monitoramento da cobertura florestal e ordenamento ambiental em parceria com diversas instituições e iniciativas ligadas ao licenciamento ambiental, à regularidade fundiária e à produção sustentável (Guimarães et al., 2013). O município foi o primeiro a sair da lista em 2010 e demonstrou que era possível atender às exigências do Ministério do Meio Ambiente e estruturar uma economia local em bases sustentáveis. Embora o avanço da soja, da mineração e da agropecuária continuem trazendo tensões e impactos ambientais que precisam ser investigados. Todavia, esta análise não é o escopo deste artigo.

Baseado na experiência de Paragominas, em 2011, a iniciativa municipal tornou-se política do estado do Pará, com a instituição do Programa Municípios Verdes, por meio Decreto estadual $n^{\circ} 54 / 2011$, em parceria com o setor produtivo, prefeituras, Ministério Público e organizações não governamentais (Guimarães et al., 2013).

O Programa possui os seguintes objetivos: (i) Promover o desenvolvimento econômico e social através do uso sustentável e conservação dos recursos naturais; (ii) Fortalecer o Sistema Municipal de Meio Ambiente com incentivo à criação dos órgãos e conselhos municipais de meio ambiente, incluindo mecanismos que facilitem a sua estruturação, aparelhamento e funcionamento regular; (iii) Compartilhar e descentralizar a agenda ambiental, o que pressupõe ações integradas entre o Governo do Estado e os municípios, e permite uma participação mais efetiva da sociedade civil e do setor produtivo.

No estado do Mato Grosso, inspirado pelo PMV, foi organizado em conjunto por instituições do terceiro setor, governos estadual e municipais o Programa Mato-grossense de Municípios Sustentáveis (PMS). Criado pelo Decreto Estadual $n^{\circ}$ 2.188/2014, o PMS tem objetivo de promover o desenvolvimento sustentável dos municípios mato-grossenses e possui o fortalecimento da gestão ambiental municipal com um dos eixos de atuação (ICV, 2014). 


\subsection{Análise dos dados de desmatamento}

A partir da análise de dados de desmatamento por município monitorados e disponibilizados pelo INPE por meio do PRODES na Amazônia é possível realizar reflexões sobre os resultados da política de priorização de municípios. Como os dados disponíveis para o desmatamento municipal, até a publicação deste artigo, são referentes até o ano de 2016, são considerados os anos de 2005 a 2016. Como não há dados de desmatamento de 2017 disponíveis, não serão consideradas as mudanças na lista de municípios prioritários publicadas em 2017. A Tabela 2 aponta o somatório da variação anual no desmatamento nos municípios da lista, fora da lista (isto é, que nunca estiveram na lista até o ano) e que saíram da lista.

Observa-se uma tendência de queda conside- rável de 2005 a 2013 nos municípios fora da lista. Após 2013, nestes dois grupos, há uma aparente tendência de ascensão. Dentre os municípios da lista, a trajetória do desmatamento é ascendente após 2011, mas há também aumento no número de municípios. É possível supor que a partir de 2011 possa ter havido um arrefecimento das ações realizadas no âmbito da política. Por exemplo, conforme observado neste trabalho, em 2011 ocorreu a última reunião do Comitê Gestor Nacional da Operação Arco Verde.

Além disso, em 2011 há um aumento considerável no número de municípios da lista, de 42 para 48 municípios, equivalente a $14 \%$. Ao aumentar o número de municípios da lista, é razoável supor que a participação do conjunto de municípios no total desmatado tende a aumentar, simplesmente porque aumentou o número total de municípios que

TABELA 2 - Desmatamento anual nos municípios em $\mathrm{Km}^{2}$ - lista, monitorados e fora da lista

\begin{tabular}{cccccc}
\hline Ano & $\begin{array}{c}\text { Municípios da } \\
\text { lista }^{1}\end{array}$ & $\begin{array}{c}\mathbf{N}^{0} \text { de municí- } \\
\text { pios na lista }\end{array}$ & $\begin{array}{c}\text { Municípios que } \\
\text { saíram da lista }\end{array}$ & $\begin{array}{c}\mathbf{N}^{0} \text { de municípios que } \\
\text { saíram da lista }\end{array}$ & $\begin{array}{c}\text { Municípios fora da lista } \\
\text { (Amazônia Legal) }\end{array}$ \\
\hline 2005 & $10.444,8^{1}$ & - & - & - & $13.446,4$ \\
2006 & $4.615,7^{1}$ & - & - & - & $6.283,7$ \\
2007 & $5.165 .8^{1}$ & - & - & - & $6.336,1$ \\
2008 & $4.782,5$ & 35 & - & - & $8.519,2$ \\
2009 & $2.870,6$ & 43 & - & - & $3.681,0$ \\
2010 & $2.268,8$ & 42 & 68,3 & 1 & $3.999,1$ \\
2011 & $2.569,6$ & 48 & 50,6 & 2 & $2.988,0$ \\
2012 & $1.732,2$ & 46 & 142,9 & 6 & $2.580,6$ \\
2013 & $2.675,0$ & 44 & 246,5 & 8 & $2.489,5$ \\
2014 & $2.426,1$ & 44 & 197,3 & 8 & $2.500,5$ \\
2015 & $3.054,5$ & 44 & 274,7 & 8 & $2.814,5$ \\
2016 & 3674,5 & 44 & 277,6 & 8 & $3.314,7$ \\
\hline
\end{tabular}

${ }^{1}$ Nos anos de 2005 a 2007 ainda não havia municípios na lista. Mas para fins de análise, foram considerados as áreas desmatadas naqueles 35 municípios da lista de 2008.

FONTE: Elaboração própria com base nos dados do PRODES/INPE 


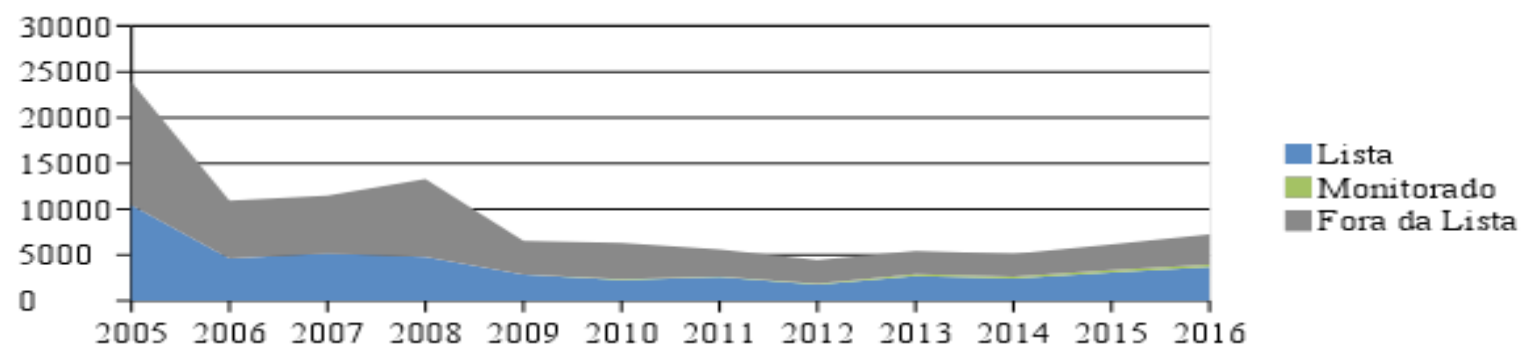

FIGURA 2 - Desmatamento anual nos municípios - lista, monitorados e fora da lista.

FONTE: Elaboração própria com base nos dados do PRODES/INPE.

serão contabilizados. Entretanto, a participação do conjunto de municípios da lista no total desmatado aumentou $30 \%$, superior ao crescimento percentual do número de municípios listados.

Interessante notar que em 2008 - primeiro ano de priorização de municípios - há um salto de desmatamento nos municípios fora da lista enquanto os municípios da lista mantêm trajetória descendente. Se, por um lado, pode ser reflexo da eficácia da política em evitar o desmatamento em municípios mais críticos em um ano de maior pressão por desmatamento, por outro, a focalização nos mais críticos pode ter reduzido a atenção nos demais, permitindo maior desmatamento.

A Figura 2 ilustra as trajetórias do somatório da variação anual no desmatamento nos municípios da lista, fora da lista e que saíram da lista.

Na Tabela 3 representa-se a evolução da participação dos três grupos - municípios na lista, fora da lista e que saíram da lista - no total do incremento do desmatamento na Amazônia. É marcante a queda na participação dos municípios críticos de 2007 para 2008, de cerca de 9 pontos percentuais. Estes municípios, que respondiam por cerca de $45 \%$ do desmatamento, passam a $36 \%$ no primeiro ano da política, passando a 44\% em 2009 (ano em que 8 municípios são incluídos na lista), reduzindo a cerca de $36 \%$ em 2010 (ano em que o primeiro município sai da lista).

Em 2011, um município é retirado da lista e sete são incluídos, passando a participação a $46 \%$. A partir de 2013, com 44 municípios na lista, a participação chega a $50 \%$, com $49,7 \%$ em 2015 , participação mais alta da série. Infere-se daí um êxito na redução do desmatamento no momento de implementação da política, mas que, com o passar do tempo, deixa de existir. A participação dos municípios da lista passa de 45\% em 2007 a cerca de $50 \%$ após 2013. Entretanto, o número de municípios da lista passa de 35 a 44, um aumento considerável ${ }^{3}$.

A Figura 3 demonstra a participação no desmatamento, de 2005 a 2016, das três classes de municípios apresentadas na Tabela 3.

Uma forma alternativa de olhar os resultados

${ }^{3}$ Como já mencionado, o simples fato de aumentar o número de município da lista tende a aumentar a participação do conjunto de municípios no total desmatado, simplesmente porque há mais elementos sendo somados. 
está em comparar todos os 52 municípios que estiveram em alguma lista até 2016 com os que nunca estiveram até então. A Tabela 4 apresenta esta comparação. Em 2007, os municípios que já estiveram na lista respondiam por $55 \%$ do desmatamento. Em 2008 há uma queda de cinco pontos percentuais, uma queda de três pontos em 2009, chegando a $43 \%$ da participação no desmatamento em 2010. Após este ano a participação cresce, variando em torno de $50 \%$. É válido destacar que a participação em 2016 é inferior à participação em 2007, o que poderia denotar um grau de efetividade da política nos municípios, apesar de um crescimento expressivo na participação após 2010.

A Figura 4 demonstra da participação no desmatamento dos municípios que estiveram em algum momento da lista até 2016 com os que nunca estiveram até então.

Em relação a efetividade da política, uma pergunta relevante a ser endereçada é: os municípios que saíram da lista conseguiram internalizar a qualidade da governança ambiental após a saída? Uma forma de ajudar a responder é observando como o desmatamento no município evoluiu após este sair da lista.

A Tabela 5 traz o somatório da participação do desmatamento nestes municípios, que salta de 1,1\% em 2010 para 3,2\% em 2012 e 4,6\% em 2013. Mas este número isoladamente é pouco ilustrativo, uma vez que o número de municípios passa de 1, 6 e 8 , respectivamente, nestes anos. Alternativamente, a tabela 5 traz a trajetória na participação no desmatamento em municípios agrupados pelo ano de saída da lista.

O município que saiu em 2010 conseguiu manter um ritmo de redução no desmatamento. $\mathrm{O}$ que saiu em 2011 observou um salto no desmatamento em 2012, seguido de queda e uma trajetória ascendente. Os municípios de 2012 reduziram o desmatamento após a saída da lista, enquanto os municípios de 2013 aumentaram o desmatamento após a saída da lista. Como as trajetórias são ambíguas,

TABELA 3 - Participação no desmatamento anual nos municípios na Amazônia Legal em \% - lista, monitorados e fora da lista.

\begin{tabular}{cccc}
\hline Ano & Municípios da lista $^{1}$ & Municípios que saíram da lista & Municípios fora da lista (Amazônia Legal) \\
\hline 2005 & 43,71 & & 56,3 \\
2006 & 42,31 & & 57,7 \\
2007 & 44,91 & & 55,1 \\
2008 & 36 & & 64,0 \\
2009 & 43,8 & 1,1 & 56,2 \\
2010 & 35,8 & 0,9 & 63,1 \\
2011 & 45,8 & 3,2 & 53,3 \\
2012 & 38,9 & 4,6 & 57,9 \\
2013 & 49,4 & 46,0 \\
\hline
\end{tabular}

${ }^{1}$ Nos anos de 2005 a 2007 ainda não havia municípios na lista. Mas para fins de análise, foram consideradas as áreas desmatadas naqueles 35 municípios da lista de 2008.

FONTE: Elaboração própria com base nos dados do PRODES/INPE. 


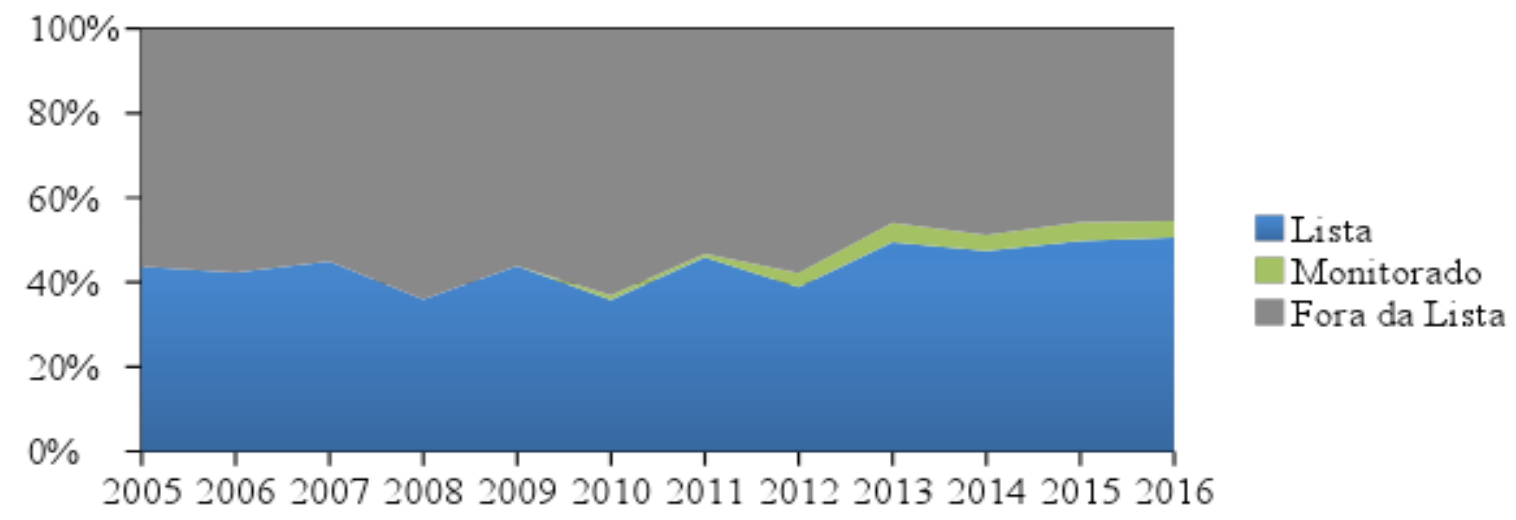

FIGURA 3 - Participação no desmatamento anual nos municípios na Amazônia Legal em \% - lista, monitorados e fora da lista. FONTE: Elaboração própria com base nos dados do PRODES/INPE

TABELA 4 - Participação no desmatamento anual nos municípios em \% - municípios que estiveram na lista em algum momento

\begin{tabular}{ccc}
\hline Ano & $\begin{array}{c}\text { Municípios que tiveram na lista em } \\
\text { algum momento }\end{array}$ & Municípios fora da lista \\
\hline 2005 & 52 & 48 \\
2006 & 56 & 44 \\
2007 & 55 & 45 \\
2008 & 50 & 50 \\
2009 & 47 & 53 \\
2010 & 43 & 57 \\
2011 & 51 & 59 \\
2012 & 47 & 49 \\
2013 & 51 & 51 \\
2014 & 49 & 49 \\
2015 & 51 & 48 \\
2016 & 52 & \\
\hline
\end{tabular}

FONTE: Elaboração própria com base nos dados do PRODES/INPE.

TABELA 5 - Dinâmica do desmatamento nos municípios monitorados - \%

\begin{tabular}{|c|c|c|c|c|c|c|c|c|}
\hline & 2009 & 2010 & 2011 & 2012 & 2013 & 2014 & 2015 & 2016 \\
\hline Monitorado em 2011 & 0,11 & 0,35 & 0,26 & 0,87 & 0,25 & 0,30 & 0,30 & 0,30 \\
\hline Monitorado em 2012 & 1,83 & 1,57 & 1,55 & 1,94 & 1,23 & 0,82 & 0,89 & 0,75 \\
\hline Monitorado em 2013 & 1,49 & 2,29 & 2,14 & 1,35 & 2,50 & 2,34 & 2,89 & 2,50 \\
\hline
\end{tabular}

FONTE: Elaboração própria com base nos dados do PRODES/INPE. 
não se pode afirmar, ao observar a participação no desmatamento, qual foi o impacto em termos de internalização da governança da conservação florestal após a saída da lista. Além disso, as eventuais oscilações na implementação de políticas relacionadas ao desmatamento pelo Governo Federal - ora com maior eficácia, ora com menor - podem gerar sinalizações e incentivos ambíguos à gestão ambiental municipal no decorrer do tempo.

A Figura 5 representa a trajetória na participação no desmatamento em municípios agrupados pelo ano de saída da lista.
Os resultados demonstram que a política teve um impacto mais significativo nos seus primeiros anos. Nos anos posteriores, não é possível observar uma trajetória de redução do desmatamento nos municípios da lista em relação aos demais. Isto parece estar relacionadas ao fato de que a política, embora formalmente em vigor, reduziu sua implementação: antes de 2017, a última atualização da lista foi em 2013 e o comitê gestor da Operação Arco Verde não se reúne desde 2011.

A publicação da atualização da lista em 2017 e o aperfeiçoamento da metodologia e das ações

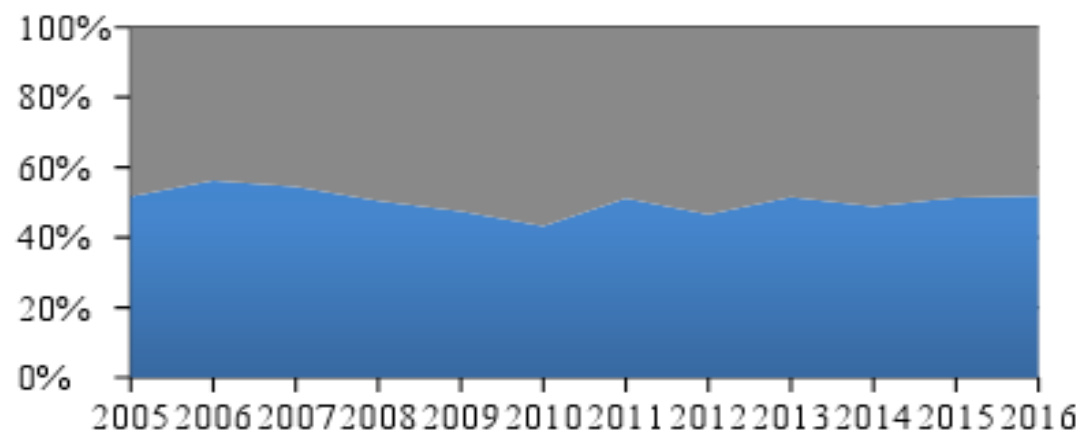

Lista em Algum momento Fora da lista

FIGURA 4 - Participação no desmatamento anual nos municípios em \% - municípios que estiveram na lista em algum momento. FONTE: Elaboração própria com base nos dados do PRODES/INPE.

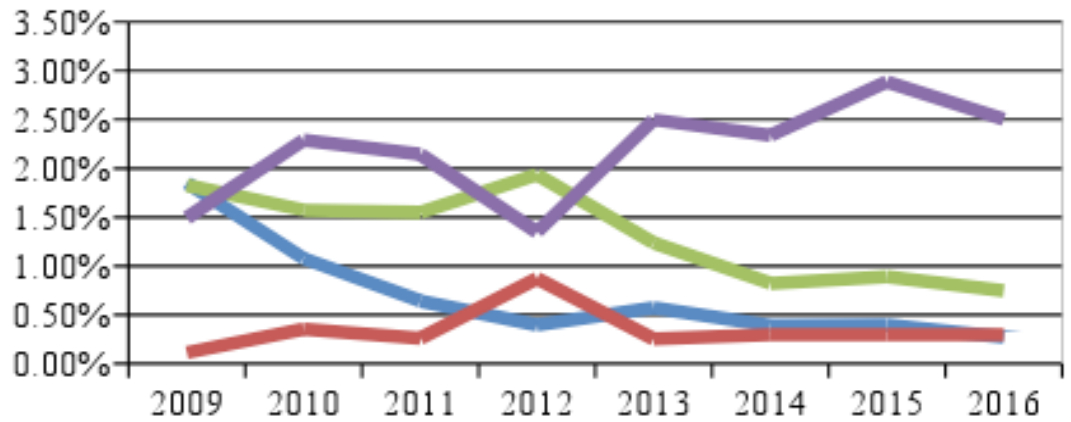

Monitorado em 2010

Monitorado em 2011

Monitorado em 2012

Monitorado em 2013

FIGURA 5 - Dinâmica do desmatamento nos municípios monitorados - \%.

FONTE: Elaboração própria com base nos dados do PRODES/INPE. 
mencionado na A 4a fase do PPCDAm trazem perspectivas positivas. A retomada da implementação pode trazer impactos positivos na gestão ambiental municipal, com consequente contribuição para as políticas do desmatamento, e possíveis novas externalidades positivas.

Esta retomada da política seria particularmente relevante em um contexto de aumento do crescimento do desmatamento a partir de 2013, embora haja perspectivas de redução em 2017. Entretanto, para isso acontecer, dependeria de muito engajamento dos formuladores e implementadores de política pública, pois o Estado brasileiro passa por uma conjuntura muito mais desafiadora que a de 2008.

A instabilidade da política brasileira atual dificulta a construção de agendas nacionais comuns, com coordenação e articulação entre os diferentes níveis de governo e sociedade, fundamentais às políticas para conservação florestal. Ainda, a restrição orçamentária, com destaque para a Emenda Constitucional 95, que limita por 20 anos os gastos públicos, aprovada em 2016, coíbe o potencial de ação governamental em todos os setores, incluindo a questão ambiental.

Este contexto impele os formuladores e implementadores de políticas públicas ambientais, o que inclui todos os níveis de governo e sociedade, a um engajamento e reinvenção no sentido de garantir a conservação florestal na Amazônia. Este esforço deve ser acompanhado do aumento de recursos orçamentários para a execução de ações pelo órgãos federais. Há de se mencionar que a publicação da nova fase do PPCDAm e a renovação da lista podem indicar que os órgãos de meio ambiente estão positivamente imbuídos neste esforço.

\section{Considerações finais}

O trabalho teve por objetivo principal avaliar os resultados da política de priorização de municípios para focalização de ações relativas à prevenção, monitoramento e controle de desmatamento no Bioma Amazônia, instituída pelo Decreto $\mathrm{N}^{\circ}$ $6.321 / 2007$.

A política teve êxito na redução do desmatamento no momento de início de sua implementação, mas, com o passar do tempo, este êxito é reduzido. Além disso, as trajetórias do desmatamento nos municípios são ambíguas não podendo se afirmar o impacto em termos de internalização da governança da conservação florestal após a saída da lista. Além das variações no esforço de implementação no âmbito da iniciativa, a ambiguidade das trajetórias possivelmente está relacionada às diferentes sinalizações políticas com o decorrer do tempo, num aspecto mais amplo relacionado à Política Ambiental.

Nos primeiros anos, além da redução do desmatamento, a política teve impactos indiretos importantes dados pela consolidação do CAR como política pública nacional para regularização ambiental dos imóveis rurais e inspiração para políticas estaduais que focalizam na governança ambiental local. O fato de a política ter tido seu êxito reduzido parece estar relacionado a ela, embora formalmente em vigor, ter tido sua implementação reduzida. A principal constatação neste sentido é de que a lista de municípios prioritários não era atualizada desde 2013. A atualização da lista em 2017 pode denotar um esforço muito positivo de se retomar a execução da política, com a revisão dos incentivos de premiação e punição, que podem aumentar sua efetividade. 
Dentre as contribuições do trabalho, é possível mencionar que este se insere no esforço mais amplo de ampliar a cultura de avaliação de Políticas Públicas, possibilitando formas de atuação do Estado mais transparentes, eficientes, eficazes, efetivos e decisões tomadas com respaldo técnico e científico. Especificamente com respeito à política de priorização de municípios, o trabalho retoma as avaliações do início de sua implementação - com base em informações de até 2011 - trazendo novos esforços e reflexões.

$\mathrm{O}$ atual contexto brasileiro lança desafios à política de conservação florestal: em meio a uma trajetória ascendente do desmatamento, com restrição de orçamento público e crise política, é necessário fortalecer mecanismos para redução do desmatamento, bem como fortalecer o orçamento dos órgãos ambientais.

A política de priorização demonstra que estimular a gestão ambiental local (com mecanismos de incentivos e punição) pode ser eficaz na estratégia de conservação florestal. Cabe aos governos, em conjunto com a sociedade, repensar e utilizar-se dessas experiências no intuito de aplicar mecanismos eficazes em um ambiente político de muitas incertezas.

Avaliações deste tipo podem contribuir com o processo de construção e tomada de decisões pelos diversos atores envolvidos nas políticas ambientais, valorizando, inclusive, o trabalho já empenhado pelos agentes públicos e sociedade na agenda de redução do desmatamento. O momento parece oportuno não apenas pelo contexto desafiador, mas pela menção na nova fase do PPCDAm, sinalizando a propensão dos atores competentes no Setor Público em empenhar esforços para melhoria desta política.
A agenda futura de pesquisa passa necessariamente pela continuidade e aprimoramento desta política e das demais relacionadas à agenda ambiental e de redução do desmatamento. Dentre as possibilidades de futuras análises estão a dinâmica da internalização e qualidade da gestão ambiental municipal e a interação das diferentes dinâmicas regionais na Amazônia em relação às diversas políticas públicas.

\section{Referências}

Albagli, S. Amazônia: fronteira geopolítica da biodiversidade. Revista Parcerias Estratégicas do MCT, 12, 6-19, 2001.

Arima, E.; Barreto, P.; Araújo, E.; Soares-Filho, B. Public policies can reduce tropical deforestation: Lessons and challenges from Brazil. Land Use Policy, 41, 465-473, 2014.

Assunção, J.; Gandour, C.; Rocha, R. Deforestation slowdown in the Legal Amazon: prices or policies. Climate Policy Initiative Working Paper, 2012.

Assunção, J.; Rocha, R. Municípios Prioritários: Reputação ou Fiscalização? Getting Greener by Going Black: The Priority Municipalities in Brazil. Climate Policy Initiative. Technical Paper, Climate Policy Iniciative, 2014.

Bacha, C. O Uso de Recursos Florestais e as Políticas Econômicas Brasileiras - Uma Visão Histórica e Parcial de um Processo de Desenvolvimento. O Uso de Recursos Florestais e as Políticas Econômicas Brasileiras Estudos Econômicos, 34(2), 393-426, 2004. doi: 10.1590/S010141612004000200007.

Bauer, A. Avaliação de impacto no Brasil: é possível mensurar impactos de programas de formação docente? Estudos em Avaliação Educacional, 21, 46, 229-251, 2010. Disponível em: http://www.fcc.org.br/pesquisa/publicacoes/eae/ arquivos/1576/1576.pdf

Becker, B. Amazônia: desenvolvimento e soberania. In: Brasil: O Estado de uma nação. Rio de Janeiro: Instituto de Pesquisa Econômica e Aplicada - IPEA.199-250, 2005. 
Boucher, D.; Elias, P.; Faires, J.; Smith, S. Deforestation success stories: Tropical nations where forest protection and reforestation policies have worked. Cambridge, MA: Union of Concerned Scientists, 8, 2014.

Carlo, S. Gestão ambiental nos municípios brasileiros: impasses e heterogeneidade. Tese (Doutorado) - Centro de Desenvolvimento Sustentável, Universidade de Brasília, Brasília, 2006.

Carvalho, P.; Oliveira, S.; Barcellos, F.; Assis, J. Gestão local e meio ambiente. Ambiente \& Sociedade, 8(1), 121-140, 2005. doi: 10.1590/S1414-753X2005000100008.

Castro, E. Dinâmica socioeconômica e desmatamento na Amazônia. Novos Cadernos NAEA, 1(8), 2, 2008. doi: 10.5801/ncn.v8i2.51.

Cunha, C. Avaliação de políticas públicas e programas governamentais: tendências recentes e experiências no Brasil. Trabalho elaborado durante o curso "The Theory and Operation of a Modern National Economy", ministrado na George Washington University, no âmbito do Programa Minerva, em 2006.

Cunha, F.; Börner, J.; Wunder, S.; Cosenza, C.; Lucena, A. The implementation costs of forest conservation policies in Brazil. Ecological Economics, 130, 209-220, 2016. doi: 10.1016/j.ecolecon.2016.07.007.

Delazeri, L. Determinantes do Desmatamento nos Municípios do Arco Verde-Amazônia Legal: uma abordagem econométrica. Revista Economia Ensaios, 30(2), 2016. doi: 10.14393/REE-v30n2a2016-1.

Fagundes, H.; De Moura, A. 05. Avaliação de programas e políticas públicas. Textos \& Contextos (Porto Alegre), 8(1), 89-103, 2009. doi: 10.15448/1677-9509.

Faria, C. A política da avaliação de políticas públicas. Revista brasileira de ciências sociais, 20, 59, 2005. doi: 10.1590/S0102-69092005000300007.

Fearnside, P. Environment: Deforestation soars in the Amazon. Nature, 521(7553), 423-423, 2015. doi: $10.1038 / 521423 b$.

Ferreira, L.; Venticinque, E.; Almeida, S. O desmatamento na Amazônia e a importância das áreas protegidas. Estudos Avançados, 19(53), 157-166, 2005. doi: 10.1590/S0103-
40142005000100010.

Guimarães, J.; Veríssimo, A.; Amaral, P.; Pinto; A.; Demachki, A. Municipios verdes caminhos para a sustentabilidade. Instituto do Homem e Meio Ambiente da Amazônia (Imazon), Pará (Brasil), 2013.

ICV. Programa Mato-grossense de Municípios Sustentáveis: Caminhos e Experiências. / Comitê Gestor. Cuiabá-MT: ICV, 2014.

INPE. Monitoramento da Cobertura Vegetal da Amazônia Sul Americana. Disponível em: < http://www.dsr.inpe.br/laf/ panamazonia/> Acesso em: 08 de janeiro de 2017. 2017a.

INPE. Taxas anuais do desmatamento - 1988 até 2016. Disponível em: < http://www.obt.inpe.br/prodes/prodes_1988_2016n.htm> Acesso em: 08 de janeiro de 2017. 2017 b.

Jann, W.; Wegrich, K. Theories of the policy cycle. Handbook of public policy analysis: Theory, politics and methods, 43-62, 2007.

Leme, T. Os municípios e a política nacional do meio ambiente. Planejamento e Políticas Públicas, 2, 35, 2011. Disponível em: http://www.ipea.gov.br/ppp/index.php/PPP/ article/view/196

Lima, D.; Pozzobon, J. Amazônia socioambiental: sustentabilidade ecológica e diversidade social. Estudos Avançados, 19(54), 45-76, 2005. doi: 10.1590/S010340142005000200004.

Maia, H.; Hargrave, J.; GóMez, .; Röper, M. Avaliação do plano de ação para prevenção e controle do desmatamento na Amazônia legal. Rio de Janeiro: GIZ, IPEA e CEPAL, 2011.

Matos, F. Análise das taxas anuais de desmatamento na Amazônia Legal a partir da relação entre autos de infração e área desmatada no período entre 2000 e 2014. 2016.

Medeiros, R. Evolução das tipologias e categorias de áreas protegidas no Brasil. Ambiente \& Sociedade, 9(1), 41-64, 2006. doi: 10.1590/S1414-753X2006000100003.

MMA - Ministério do Meio Ambiente. Plano de Ação para prevenção e controle do desmatamento na Amazônia Legal (PPCDAm): 3a fase (2012-2015) pelo uso sustentável e 
conservação da Floresta. Ministério do Meio Ambiente e Grupo Permanente de Trabalho Interministerial. Brasília: MMA, 2013.

MMA - Ministério do Meio Ambiente. Plano de Ação para prevenção e controle do desmatamento na Amazônia Legal (PPCDAm): 4a fase (2016-2020). Brasília: MMA, 2016.

MMA - Ministério do Meio Ambiente. Lista de Municípios Prioritários da Amazônia. Disponível em: < http://combateaodesmatamento.mma.gov.br/municipios-prioritarios $>$ Acesso em: 11 de novembro de 2017. 2017.

Nepstad, D. Slowing Amazon deforestation through public policy and. Science, 1248525, 1118, 344, 2014. doi: 10.1126/science. 1248525 .

Neves, E. Política ambiental, municípios e cooperação intergovernamental no Brasil. Estudos Avançados, 26(74), 137-150, 2012. doi: 10.1590/S0103-40142012000100010.

Neves, E. O Processo de Municipalização da Estratégia de Prevenção e Combate ao Desmatamento na Amazônia: Estudos de casos sobre municípios integrantes da Lista de Municípios Prioritários do Ministério do Meio Ambiente, 2016.

OCDE. Saving Biological Diversity: Economic Incentives, OCDE, Paris, 1996.

Pires, M. O cadastro ambiental rural: das origens às perspectivas para a política ambiental. Brasília: Conservação Internacional, 2013.
Ramos, M.; Schabbach, L.. O estado da arte da avaliação de políticas públicas: conceituação e exemplos de avaliação no Brasil. Revista de Administração Pública, 46(5), 12711294, 2012. Disponível em: http://bibliotecadigital.fgv.br/ ojs/index.php/rap/article/view/7140

Rua, M. Análise de políticas públicas: conceitos básicos. Manuscrito, elaborado para el Programa de Apoyo a la Gerencia Social en Brasil. Banco Interamericano de Desarrollo: INDES, 1997.

Rua, M. Políticas públicas / Maria das Graças Rua. - Florianópolis : Departamento de Ciências da Administração / UFSC; [Brasília] : CAPES : UAB, 2009.

Scardua, F.; Bursztyn, M. Descentralização da política ambiental no Brasil. Sociedade \& Estado, 8, 1-2, 291-314, 2003. doi: 10.1590/S0102-69922003000100014

Schmitt, J.; Scardua, F. A descentralização das competências ambientais e a fiscalização do desmatamento na Amazônia. Revista de Administração Pública, 49(5), 1121-1142, 2015. doi: 0.1590/0034-7612131456.

Souza, C. Políticas públicas: questões temáticas e de pesquisa. Caderno CRH, 39, 11-24, 2003. Disponível em: https:// portalseer.ufba.br/index.php/crh/article/view/18743/12116 